\title{
International Business and the Post-2015 Agenda
}

\author{
Maria Alejandra Gonzalez-Perez, Universidad EAFIT, Colombia
}

Right NOW, COMPETITIVE BUSINESS companies, managers and academics face a universal challenge: being globally competitive, while at the same time locally relevant. From the $13^{\text {th }}$ to the $16^{\text {th }}$ of October 2014 the World Investment Forum (WIF) took place at Palais des Nations in Geneva; the Academy of International Business (AIB) was one of the partner organisations of this event and Prof. Helena Barnard from the Gordon Institute of Business Science (GIBS) at the University of Pretoria in South Africa and myself were selected as academics from developing countries to participate in the WIF 2014 representing the AIB.

For over 150 years Geneva has witnessed significant sequences of global understanding and a transformation (through domestic and international challenges) in opportunities, which have been of universal interest, such as human rights, health, trade, human development and investment. According to James Zhan, Director of the Investment and Enterprise division at UNCTAD and co-editor of the World Investment Report, "we are in a moment of paradigm shift from liberalisation to regulation".

In the framework of the WIF, a multi-disciplinary academic conference organised in cooperation with AIB, UNCTAD, the European International Business Academy (EIBA), the Society of International Economic Law (SIEL) and the Graduate Institute at Geneva took place. The aim of this specific conference was to facilitate a multi-disciplinary dialogue on a policy-oriented research agenda, focused on the role of corporate investment in the post-2015 objectives for sustainable development. In order to accomplish this aim, participants who had previously submitted their research background or paper proposals were divided into six specific parallel sections (a. opportunities and challenges; b. systemic issues and institutions; c. development and investment strategies; d. responsibility and sustainability; e. investment impact; and f. coherence and synergies), and two or three experts were assigned as chairs for each session. These parallel sections were followed by a plenary session titled "shaping a multidisciplinary policy research agenda on investment for development", which was led by James Zhan from UNCTAD, Jean-Louis Arcand from the Graduate Institute Geneva, Peter Buckley from the University of Leeds, Robert Grosse (Immediate Past President of AIB) from the American University of Sharjah and Gabrielle Marceau (President of the Society of International Law) from the Geneva University Law School. During this section the feedback of the parallel tracks was received by their designated chairs.

2015 is a year for major international multi-stakeholder negotiations. The millennium development goals (MDGs) in the post-2015 agenda were formulated as vital targets for the liberty, security and prosperity of humanity. In the words of Mr. Didier Burhalter, President of the Swiss Confederation for the year 2014 and one of the hosts at the WIF 2014, "States alone won't be able to reach the development goals, public and private sectors and markets must cooperate, and work together towards realist business plans for catalysing sustainable advancements towards achieving the MDGs".

As the 20 targets of the eight Millennium Development Goals (MDGs) will expire in 2015, a new set of ambitious Sustainable Development Goals (SDGs) were decided by committed heads of state during the Rio+20 summit of the United Nations in 2012 to be formulated and met by 2030. The underlying distinctive feature of these post-2015 SDGs was to align international economic liberalisation with the sustainable development agenda by stimulating the role of the private sector to complement the governments' responsibility in order to meet environmental, social and economic goals for their citizens while tackling inequality and eradicating poverty in all its forms. Amongst the differences between the MDGs and the SDGs are: (i) the number of goals and objectives (while these were only eight with 20 targets for the MDGs, the new SDGs are 17 and have 126 defined targets); (ii) the

\section{(s) In 2013, global foreign direct investments flows increased by 9 per cent and are expected to maintain this growth in the following years}

geographical scope (the MDGs were focused on developing countries, while the SGDs are applied to all countries); and (iii) the means of implementation (while the MDGs paid limited attention to implementation, the SDGs emphasise the implementation of objectives and provide a space important for the private sector). Nonetheless, there are several economic/financial, environmental and structural constraints related to inequality to be urgently addressed with the design and implementation of measures and innovative policies locally and internationally at both developed and developing countries.

In 2013, global foreign direct investments flows increased by 9 per cent and are expected to maintain this growth in the following years 
(UNCTAD, 2014). This is a promising tendency after the decline in 2012 and implies a good prospective for international investment to spur the attainment of the post-2015 sustainable goals. International businesses have crucial roles in attaining these universal development targets, through enhancing their positive economic, social and environmental impacts by paying fair taxes, reassuring positive local effects, creating good quality employment, recruiting local staff, investing in the communities where they work and live, stimulating exports, fostering rights, promoting a greener economy, cooperating with governments, nurturing inter-cultural harmony, encouraging the coordination of local SMEs in global production networks, concentrating in creating infrastructure, advancing global connectivity and interconnection with local firms and transferring technology, capital and leveraging resources and linkages to host countries. sustainable development is a huge challenge and the world is demanding a re-orientation towards sustainable and resilient investment".

Furthermore, Jeffrey Sachs, the director of The Earth Institute at Columbia University, urged for developing regional regulatory systems, where rules need to be transparent and consistent from one country to another; however, negotiating at a global level has proved to be hard, and not necessarily effective. "There is not such thing as a successful free market, and this is why markets and governments require to co-operate", stated Sachs.

To address these challenges proposed in the post-2015 development agenda, international business academics have imperative responsibilities in identifying new research areas. James Zhang from UNCTAD and AIB's Fellow, Prof. Robert E. Grosse, highlighted that it requires a multidisciplinary approach given its complexity; future research needs to be forward looking but based both on evidence from the past and on policy oriented towards the future. expertise gaps

There are evident challenges in financing development, especially in economically deprived economies that will demand active policies and innovative financial instruments to fill investment, technological and expertise gaps. Business objectives and public expectations have been antagonist concepts. Mr. Mukhisa Kituyi, Secretary-General of UNCTAD, has, during the WIF 2014, raised awareness of investment in sustainable development and exposed the international defiance of doubling private investment, as public investment is not enough. In Mr. Kituyi's own words "the international community must tackle these challenges and this implies policy dilemmas for both governments and business. We don't need to wait other 10 years, it is a global responsibility to act now". In order to do this, capital markets for sustainable development that channel investment for development projects are needed. This would involve new and innovative forms of partnerships and alliances; national and international policy support; changing business mind-sets and identifying and prioritizing working business frameworks for sustainable development (such as establishing good governance systems, fostering a positive attitude towards technological and science-based solutions and providing incentives for infrastructure investment agreements, amongst many others).

Philanthropic initiatives and donations against poverty alleviation and for integration of the economically marginalised have proven not to be sufficient and channels are required to push investments towards development. As presented by UN Goodwill Ambassador and professional footballer, Didier Drogba "the most ambitious are the goals the more money we are going to need to fund them". In a corresponding statement, Prince Charles of Wales pronounced that "finding ways to fund in the post-2015 development agenda have been identified. As there is a predicted new era of regulations, agreements and re-negotiation of old treaties, the current demand for policy analysis and technical advising is likely to be increased by both governments and the private sector. This denotes substantial requirement for robust quantitative and qualitative data at different levels (including at the activity level) as well as networking (amongst academics, governments and the private sector). Also, it is foreseeing an incremental role of institutions; therefore, issues such as the rule-of-the-law, promotion (and protection) of investment, intellectual property rights and anti-competitive issues are likely to be strengthened. As identified by Prof. Peter Buckley and Prof. Sumit Kundu, trends towards comparative sub-regional and cross-city studies (instead of cross-national or cross-regional studies) are expected to gain popularity since the current evidence shows that it is the cities (or very specific locations) that attract most of the FDI (rather than countries). Furthermore, the research area of sustainability and corporate social responsibility needs to cover the identification of meaningful instruments and incentives for both managers and firms to deliver socially relevant results, while been profitable; market and law-driven penalties on firms and managers who failed to meet societal expectations also emerge as a necessity. Furthermore, the fact that new spaces for multi and interdisciplinary research have been recently opened up was stressed. For instance, the emergence and consolidation of global production networks requires consideration of the space dimensions studied by geography; global value chains require economic and sociological perspectives to understand the role of firms in the chains and the power asymmetries in linkages so planning, coordination and orchestration could happen beyond the firm level; and to modify 
international investors and managers' mind-sets towards development and pro-poor oriented businesses as well as towards integrating competition and cooperation, a psychological perspective would offer a valuable complement. Increasingly individual and institutional investors have been forced to think long-term, or as stated at the WIF 2014 by Mark Wilson, CEO at Aviva's group "there is a growing demand and supply of systematic and transparent data for investment decisions".

Another important contribution during the UNCTAD's WIF 2014, was the roundtable discussion organised by AIB on "Global connectivity as the basis for local value creation: Implications for development for and sustainability". This roundtable was chaired and organised by Prof. Ram Mudambi from Temple University and was shared with Prof. Peter Buckley from Leeds University, Felipe Monteiro and Miguel Torres from Aveiro University and Prof. Jeremy Clegg also from Leeds University. At this roundtable, three megatrends in the world economy were underlined: (i) the shift from trade-in-goods to trade-in-activities; (ii) the rise of knowledge-intensive intangibles, which demand knowledge internalisation; and (iii) the rise of emerging markets.

In general, at the WIF 2014, there was a broad call of having investment as an umbrella for the post-2015 development agenda in the financial based economy. In order to identify the impact of investment, Khalid Nadvi from the University of Manchester proposed a series of core questions: what makes investment sticky?; what kind of investments are more sticky?; which institutions promote these investments? and what kind of policies need to be framed for investors? The post-2015 era offers international business academics an unprecedented opportunity for making enormous impact by conciliating AIB analytical perspectives, and technical expertise, with people, planet and policy-oriented research.

With all my heart I really would like to express my immense gratitude to Prof. Robert Grosse, Prof. Ram Mudambi, Prof. Jeremy Clegg, Prof. Tomas Hult, Dr. Tunga Kiyak, and the other AIB Executive members for giving me this amazingly inspiring experience, in which I realised that to be an active part of AIB makes total sense for those (as me) who believe in brighter future for our world.

\section{Reference}

UNCTAD 2014. World Investment Report 2014. Investing in the SDGs: An action plan. Available online at: http://unctad.org/en/PublicationsLibrary/wir2014_en.pdf

Maria-Alejandra Gonzalez-Perez (mgonza40@eafit.edu.co) is Full Professor of Management at Universidad EAFIT, Colombia. She is the coordinator of the Colombian universities in the virtual institute of the United Nations Conference for Trade and Development (UNCTAD), board member of the AIB-LAT chapter, and Editorin-Chief of the journal AD-minister. She has co-edited eight books, and has published several academic papers and book chapters in the areas of internationalization, corporate social responsibility and international migration. 